\title{
Outcomes of occasional cannabis use in adolescence: 10-year follow-up study in Victoria, Australia
}

\author{
Louisa Degenhardt, Carolyn Coffey, John B. Carlin, Wendy Swift, Elya Moore and George C. Patton
}

\section{Background}

Regular adolescent cannabis use predicts a range of later drug use and psychosocial problems. Little is known about whether occasional cannabis use carries similar risks.

\begin{abstract}
Aims
To examine associations between occasional cannabis use during adolescence and psychosocial and drug use outcomes in young adulthood; and modification of these associations according to the trajectory of cannabis use between adolescence and age 20 years, and other potential risk factors.

\section{Method}

A 10-year eight-wave cohort study of a representative sample of 1943 secondary school students followed from 14.9 years to 24 years.
\end{abstract}

\section{Results}

Occasional adolescent cannabis users who continued occasional use into early adulthood had higher risks of later alcohol and tobacco dependence and illicit drug use, as well as being less likely to complete a post-secondary qualification than non-users. Those using cannabis at least weekly either during adolescence or at age 20 were at highest risk of drug use problems in young adulthood. Adjustment for smoking in adolescence reduced the association with later educational achievement, but associations with drug use problems remained.

\section{Conclusions}

Occasional adolescent cannabis use predicts later drug use and educational problems. Partial mediation by tobacco use raises a possibility that differential peer affiliation may play a role.

\section{Declaration of interest}

None.
Cannabis use in adolescence has been linked to suboptimal adjustment in young adulthood, typically for those who begin or progress to heavy use. ${ }^{1,2}$ Although common in many countries, ${ }^{3}$ most adolescents use cannabis infrequently and it remains unclear whether they are also at risk of negative outcomes. Little prospective research has examined the later life circumstances of adolescent cannabis users who do not progress to heavier use. In one small study of children $(n=85)$ raised in California during the 1970s, children who experimented with cannabis were reportedly better adjusted psychologically than those who abstained until 18 years. ${ }^{4}$ This finding was not replicated in a more recent Californian study which reported that adolescent abstainers had better peer, family and school engagement and less 'deviant behaviour' at 23 years than experimenters. ${ }^{5}$ In this paper we report data from a 10-year population-based cohort study, focusing on: (a) associations between occasional cannabis use during adolescence and psychosocial and drug use outcomes in young adulthood (20-24 years); and (b) modification of these associations according to the trajectory of cannabis use between adolescence and age 20 years, and according to other potential risk factors. We focused in particular on the effect of adjustment for cigarette smoking in adolescence, because of its strong association with cannabis use.

\section{Method}

\section{Sample}

We conducted an eight-wave cohort study, 1992-2003, examining health among young people in Victoria, Australia. Data collection was approved by The Royal Children's Hospital's Ethics in Human Research Committee. The cohort was a representative sample of Victorian mid-secondary school adolescents in 1992, defined in a two-stage cluster sample, with two classes selected at random from a state-wide sample of 44 schools, one class entering the study in year nine, at 13-14 years of age (wave 1) and the second 6 months later (wave 2). Participants were interviewed at four 6-month intervals during the teens (waves 3-6) with two follow-ups in young adulthood: 20-21 years (wave 7) and 24-25 years (wave 8 ). In waves $1-6$, participants self-administered the questionnaire on laptop computers with telephone follow-up of those absent from school. Waves 7 and 8 were undertaken using computer-assisted telephone interviews. ${ }^{6}$

From a total sample of 2032 students, 1943 (96\%) participated at least once during the adolescent phase (Fig. 1). In wave 8 (April 2001 to April 2003), 1520 were interviewed. Reasons for non-completion at wave 8 were refusal $(n=269)$, loss of contact $(n=150)$ and death $(n=4)$. In this sample, participation from waves 1 to 6 was: 6 waves, $n=543$; 5 waves, $n=617 ; 4$ waves, $n=192$; 3 waves, $n=56$; 2 waves, $n=43$; 1 wave, $n=69$.

\section{Measures}

\section{Background measures}

These included school location, place of birth, parental education and employment status.

\section{Adolescent cannabis use (waves 1-6)}

Past 6-month use was categorised as 'none', 'less than weekly' (occasional) and 'weekly-daily' (weekly+). Individuals were classified according to maximum frequency in waves 1-6 (maximum adolescent use). Frequency of use was assessed without specifying method or dose.

\section{Other adolescent measures}

Tobacco smoking was recorded using a 7-day retrospective diary and maximum smoking frequency (waves 1-6). Occasional 


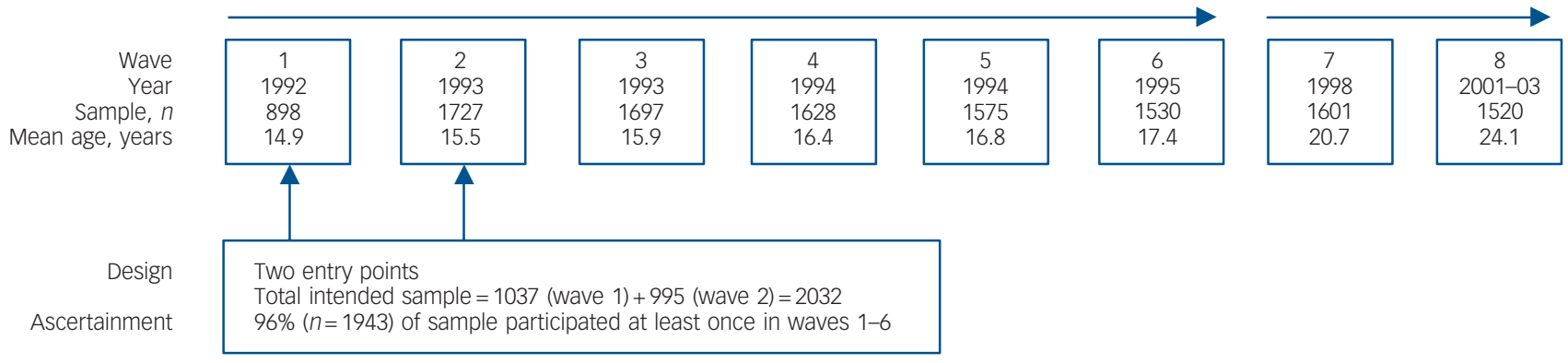

Fig. 1 Sampling and ascertainment in the Victorian Adolescent Health Cohort, 1992-2003.

smoking included any smoking within the past month; daily smoking including smoking 6-7 days of the past week.

Long-term high alcohol risk was assessed using a retrospective 1-week diary which provided estimates of alcohol consumed. Participants drinking more than $280 \mathrm{~g}$ in the previous week were classified as risky drinkers, according to 2007 draft Australian guidelines.?

Symptoms of depression and anxiety were assessed at each wave using the computerised revised Clinical Interview Schedule (CIS-R). Participants with scores $>11^{8-11}$ in any wave were classified as symptomatic.

\section{Young adulthood cannabis use (waves 7 and 8)}

Maximum past-year cannabis use was categorised into: $<5$ times (none); $>5$ times but less than weekly (occasional); and weekly or more (weekly+).

\section{Other outcomes at 24 years (wave 8)}

Post-school qualifications and current receipt of government benefits were identified in the final wave. Symptoms of depression and anxiety were assessed with the General Health Questionnaire (GHQ-12), ${ }^{12}$ and were dichotomised at a score $>2$, a threshold believed to delineate a mixed depression-anxiety state at a lower level than syndromes of major depression and anxiety disorder but where clinical intervention would be appropriate. ${ }^{9,10}$

Those who had smoked cigarettes within the past month were also identified in wave 8 . Nicotine dependence was measured using the Fagerstrom Test for Nicotine Dependence (FTND) and was defined as a score of 4 or more, corresponding to a cut-point of 7 or more on the Fagerstrom Tolerance Questionnaire. ${ }^{13}$ Alcohol dependence (DSM-IV) in the past year was assessed using the Composite International Diagnostic Interview 2.1 (CIDI). ${ }^{14}$ DSM-IV cannabis dependence among past-year weekly+ users was also assessed using the CIDI. Other illicit drug use included amfetamine, ecstasy and cocaine.

\section{Analysis}

We graphed the gender-adjusted prevalence of young adult outcomes according to adolescent cannabis use, stratified by cannabis use frequency at 20 years. Gender-adjusted proportions were obtained using predicted values from logistic regression models. Associations between categories of adolescent cannabis use and outcomes at 24 years were assessed using odds ratios. Wald tests and confidence intervals (CI) were used to assess statistical significance and precision.

Around 22\% of the original Victorian Adolescent Health Cohort Survey participants were not interviewed for wave 8 data, and a minority provided data at all waves. Consequently, the results of 'complete-case' analyses based on only those with complete data at all waves could potentially be biased. Analyses were therefore performed using the method of multiple imputation ${ }^{15}$ to allow for missing data on outcomes and predictor variables. This method has advantages over simpler imputation methods such as mean substitution and last observation carried forward, both in its potential to reduce bias and in the appropriate accounting for variance due to uncertainty about the true unobserved values.

Under the multiple imputation method, several copies of the data-set are created using a modelling process that imputes a value for each missing item, and final analyses are obtained by combining the results obtained by applying standard completedata methods to each of the imputed data-sets. Imputed values are randomly drawn using a modelling process that allows for uncertainty in the model parameters, and includes predictive information from related variables that may or may not have missing values themselves. In this study, a multivariate normal model was used to impute the missing data to create five different complete data-sets used for the analyses of this paper.

Variables measuring alcohol and drug use, and variables known to be associated with alcohol and drug use, from all eight waves were included in the imputation model, along with key sociodemographic covariates (gender, age, rural/urban residence and parental education). This was done with the stand-alone software package NORM for Windows, applying adaptive rounding post-imputation for binary measures. ${ }^{16}$

Data analysis used Stata 10.0 for Windows with multiple imputation analysis performed using special-purpose Stata commands. ${ }^{17}$ Parameters were estimated by averaging across the imputed data-sets with Wald-type confidence intervals obtained under multiple imputation using Rubin's combination rules. ${ }^{15}$

\section{Results}

A third of the cohort (34\%; 95\% CI 32-37) had used cannabis in the past 6 months in at least one adolescent wave: 331 users $(64 \%$, 95\% CI 59-68) reported only occasional use and 190 (36\%, 95\% CI 32-41) reported weekly+ use. In the first adult wave (20 years, wave 7), $60 \%$ reported using cannabis, of whom $77 \%(n=702)$ used occasionally and $23 \%(n=208)$ used weekly+. At 24 years (wave 8$), 33 \%(n=508)$ used cannabis, of whom $63 \%(n=318)$ reported occasional use and $37 \%(n=190)$ reported weekly+ use.

\section{Association between adolescent cannabis use, background factors and adolescent measures}

Adolescent cannabis use was less common in females and in participants born outside Australia (Table 1). Weekly+ users were less likely to have parents with low education, and were more 
Table 1 Association of adolescent cannabis use with background factors and other adolescent measures in 1520 cohort participants

\begin{tabular}{|c|c|c|c|c|c|c|}
\hline \multirow[b]{3}{*}{ Measure } & \multirow[b]{3}{*}{$n^{\mathrm{a}}$} & \multicolumn{5}{|c|}{ Maximum adolescent cannabis use (waves $1-6$ ) } \\
\hline & & \multirow{2}{*}{$\begin{array}{c}\text { None }(n=999) \\
n(\%)^{\mathrm{b}}\end{array}$} & \multicolumn{2}{|c|}{ Occasional use $(n=331)$} & \multicolumn{2}{|c|}{ Weekly+ use $(n=190)$} \\
\hline & & & $n(\%)$ & $\mathrm{OR}^{\mathrm{C}}(95 \% \mathrm{Cl})$ & $n(\%)$ & $\mathrm{OR}^{\mathrm{C}}(95 \% \mathrm{Cl})$ \\
\hline \multicolumn{7}{|l|}{ Background factors } \\
\hline \multicolumn{7}{|l|}{ Gender } \\
\hline Female & 824 & $582(71)$ & $162(20)$ & 1 & $80(10)$ & 1 \\
\hline Male & 696 & $417(60)$ & $169(24)$ & $1.5(1.1-1.9)$ & $110(16)$ & $1.9(1.4-2.7)$ \\
\hline \multicolumn{7}{|l|}{ Australian birth } \\
\hline Yes & 1339 & $857(64)$ & $303(23)$ & 1 & $180(13)$ & 1 \\
\hline No & 181 & $143(79)$ & $28(15)$ & $0.55(0.35-0.89)$ & $10(6)$ & $0.35(0.17-0.69)$ \\
\hline \multicolumn{7}{|l|}{ Parental education } \\
\hline Parent completed high school & 1035 & $674(65)$ & $225(22)$ & 1 & $136(13)$ & 1 \\
\hline Low parental education & 485 & $325(67)$ & $106(22)$ & $0.98(0.74-1.3)$ & $54(11)$ & $0.82(0.57-1.18)$ \\
\hline \multicolumn{7}{|l|}{ School } \\
\hline Rural & 398 & $263(66)$ & $90(33)$ & 1 & $45(11)$ & 1 \\
\hline Melbourne metropolitan & 1122 & $736(66)$ & $241(21)$ & $0.96(0.69-1.3)$ & $145(13)$ & $1.2(0.80-1.7)$ \\
\hline \multicolumn{7}{|l|}{ Adolescent measures (waves 1-6) } \\
\hline \multicolumn{7}{|l|}{ Depression/anxiety symptoms } \\
\hline No & 789 & $570(72)$ & $153(19)$ & 1 & $67(8)$ & 1 \\
\hline Yes & 731 & $430(59)$ & $178(24)$ & $1.5(1.2-2.1)$ & $123(17)$ & $2.4(1.7-3.5)$ \\
\hline \multicolumn{7}{|l|}{ High-risk alcohol use } \\
\hline No & 1373 & $960(70)$ & $288(21)$ & 1 & $125(9)$ & 1 \\
\hline Yes & 147 & $40(27)$ & $42(29)$ & $3.6(1.9-6.8)$ & $65(44)$ & $13(7.5-22)$ \\
\hline \multicolumn{7}{|l|}{ Cigarette smoking } \\
\hline No & 805 & $709(88)$ & $81(10)$ & $1(1)$ & $16(2)$ & 1 \\
\hline Yes & 715 & $290(41)$ & $250(35)$ & $7.5(5.6-10)$ & $174(24)$ & $27(15-49)$ \\
\hline
\end{tabular}

likely to have attended a metropolitan school, than non-users. Depression/anxiety symptoms, alcohol use and cigarette smoking were more likely among both occasional and weekly+ cannabis users compared with non-users.

Adolescent cigarette smoking was strongly associated with cannabis use. Eight in ten $(81 \%)$ adolescent cannabis users also reported cigarette smoking, and 59\% of smokers reported cannabis use. There was no evidence of effect modification by gender (each interaction Wald chi-squared $P>0.1$ ).

Young adult outcomes according to level and trajectory of adolescent cannabis use at 20 years

We classified individuals according to their cannabis use trajectory between the adolescent phase and 20 years: $42 \%$ of non-users in adolescence had initiated cannabis use by 20 years, typically occasional use $(90 \%)$. Of the 331 adolescent occasional users, 28 $(8 \%)$ abstained at 20 years, $236(71 \%)$ persisted with that level of use, and $67(20 \%)$ escalated to weekly+ use.

Figure 2 displays prevalence estimates of outcomes at age 24 years according to adolescent-onset cannabis use, and frequency of cannabis use at age 20 years, adjusted for gender. For the psychosocial outcomes (post-school qualifications, receipt of welfare, and depression/anxiety), persistent weekly users (those using weekly in adolescence and adulthood) had worse outcomes compared with those who never used, but there was considerable overlap in the confidence intervals around estimates for other categories of users. There was possibly a trend to greater risk of not having post-school qualifications with increasing adolescent cannabis use, which we explore in more detail below.

In contrast, patterns in the estimates and confidence intervals for substance use outcomes could be distinguished more clearly, particularly with illicit drugs, where there was a tendency for risk to increase if cannabis use at 20 years was higher. For example, adolescent occasional cannabis users who progressed to weekly+ use at 20 years were more likely to meet criteria for cannabis dependence and use other illicit drugs at 24 years than occasional cannabis users who did not escalate their use.

\section{Young adult outcomes according to level of adolescent cannabis} use

Adolescent cannabis users were less likely than non-users to have gained post-school qualifications by 24 years (Table 2). This association remained after adjustment for background factors and adolescent alcohol use and depressive symptoms, but further adjustment for adolescent cigarette smoking substantially reduced the association (Table 2). Similarly, the association between weekly+ cannabis use and government welfare at 24 years was reduced after additional adjustment for adolescent smoking.

Both alcohol and nicotine dependence at 24 years occurred more often among adolescent cannabis users, with occasional users intermediate in risk level between non-users and weekly+ users. However, adjustment for adolescent cigarette use accounted almost entirely for these associations.

All drug use outcomes at 24 years were more common among adolescent cannabis users than non-users, even after adjustment. Occasional adolescent cannabis users were at a risk that was intermediate between the non-users and the more frequent users.

\section{Discussion}

Different levels and trajectories of adolescent cannabis use were associated with different risks for drug use in young adulthood. Those who were, or became, heavier users were at greatest risk, whereas those who maintained a stable, occasional pattern of use - the most populous group of adolescent-onset cannabis users - were at less marked, but still elevated, risk of drug use problems at age 24 years. Occasional users in adolescence who persisted with occasional use were at higher risk for drug use and drug use 


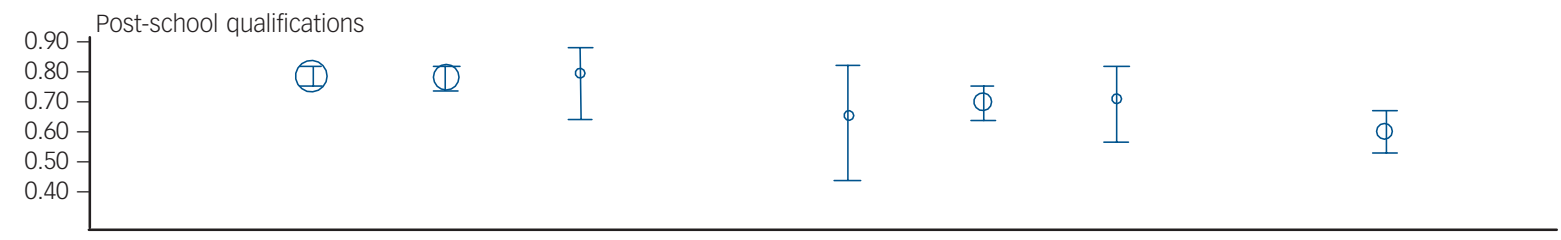

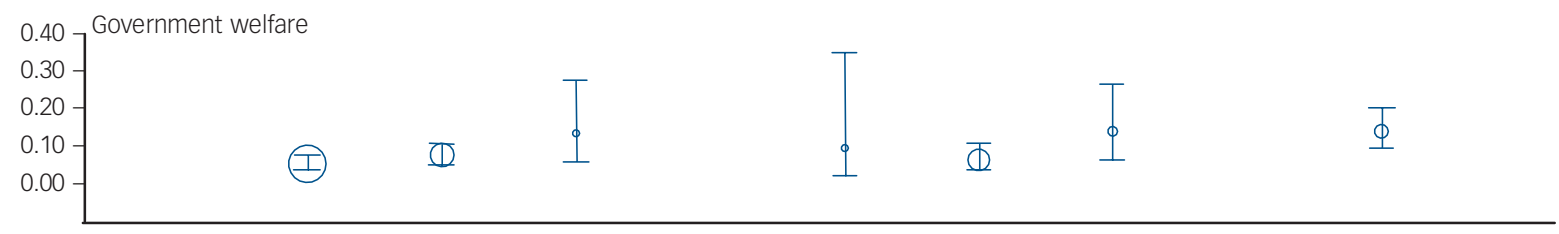

$\left.\begin{array}{l}0.40 \\ 0.30 \\ 0.20 \\ 0.10\end{array}\right]$

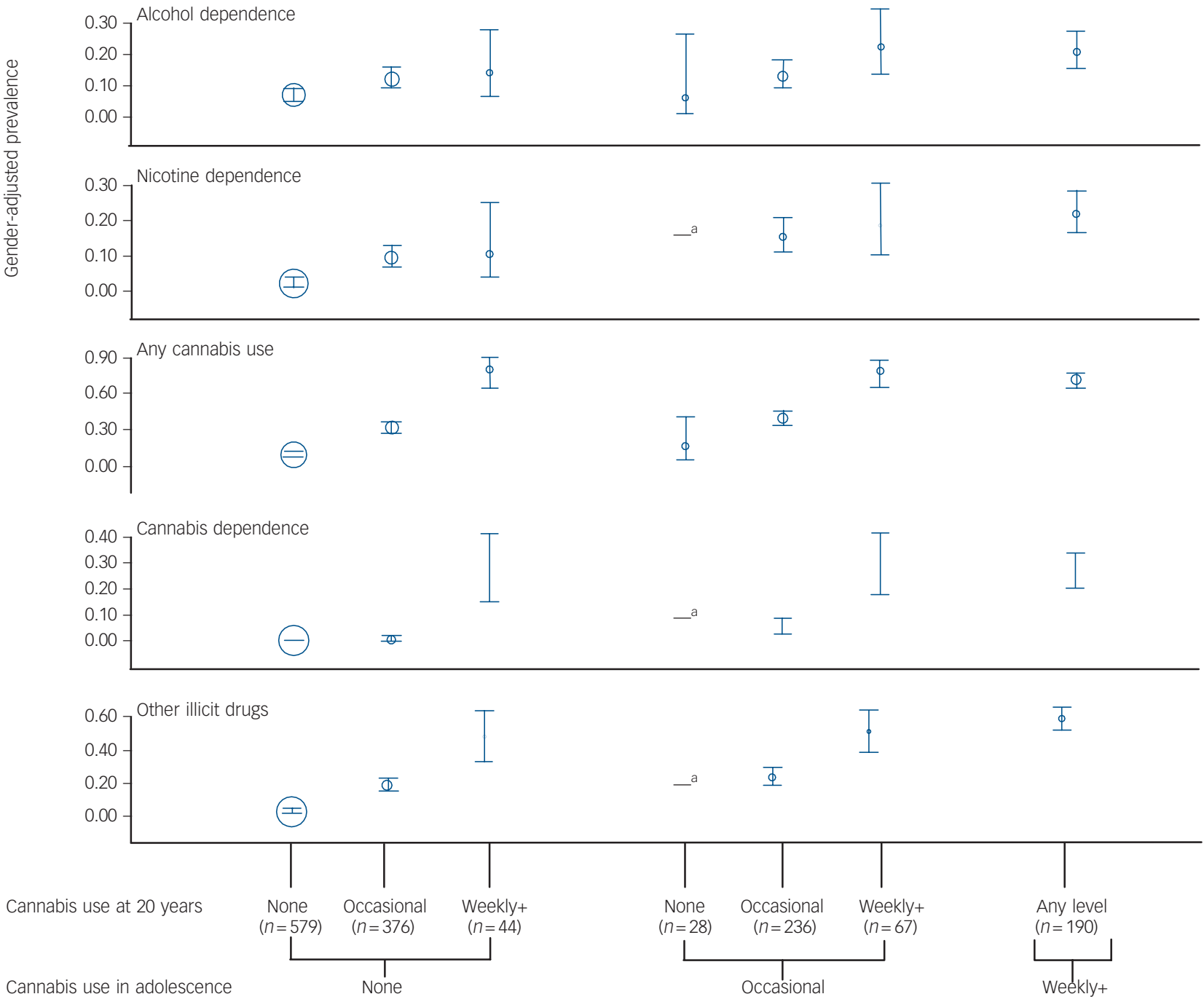

Fig. 2 Gender-adjusted prevalence of each outcome at age 24 years according to level of cannabis use during adolescence, and then by level of cannabis use at age 20 years. The diameter of the circle reflects the precision of the estimate (essentially the size of the subgroup); the vertical lines represent the $95 \%$ confidence interval around the estimate.

a. Cell frequencies were too small to allow for sensible estimation of proportion and standard errors. 
Table 2 Association of cannabis use in adolescence with psychosocial outcomes and substance use at 24 years in 1520 cohort participants, adjusted progressively for: gender; gender, background factors, adolescent depression and alcohol use; and gender, background factors, adolescent depression, alcohol use and cigarette smoking

\begin{tabular}{|c|c|c|c|c|c|c|c|c|}
\hline \multirow[b]{3}{*}{$\begin{array}{l}\text { Maximum level of } \\
\text { adolescent cannabis } \\
\text { use (waves 1-6) }\end{array}$} & \multicolumn{8}{|c|}{ Outcome at 24 years (wave 8 ) } \\
\hline & \multicolumn{3}{|c|}{ Psychosocial outcomes } & \multicolumn{2}{|c|}{ Licit substance use } & \multicolumn{3}{|c|}{ Illicit substance use } \\
\hline & $\begin{array}{l}\text { Post-school } \\
\text { qualifications }{ }^{\mathrm{a}} \\
(n=1130)\end{array}$ & $\begin{array}{l}\text { Government } \\
\text { welfare } \\
(n=120)\end{array}$ & $\begin{array}{l}\text { Depression/ } \\
\text { anxiety (GHQ } \\
>2)(n=321)\end{array}$ & $\begin{array}{l}\text { Alcohol } \\
\text { dependence } \\
(n=187)\end{array}$ & $\begin{array}{l}\text { Nicotine } \\
\text { dependence } \\
(n=147)\end{array}$ & $\begin{array}{l}\text { Any } \\
\text { cannabis use } \\
(n=508)\end{array}$ & $\begin{array}{l}\text { Cannabis } \\
\text { dependence } \\
(n=111)\end{array}$ & $\begin{array}{l}\text { Other } \\
\text { substances } \\
(n=236)\end{array}$ \\
\hline \multicolumn{9}{|l|}{ No use $(n=999)$} \\
\hline$n(\%)^{\mathrm{b}}$ & $786(79)$ & $67(7)$ & $204(20)$ & $187(9)$ & $55(5)$ & $216(22)$ & $15(1)$ & $108(11)$ \\
\hline OR & 1 & 1 & 1 & 1 & 1 & 1 & 1 & 1 \\
\hline \multicolumn{9}{|l|}{ Occasional use $(n=331)$} \\
\hline$n(\%)$ & $230(70)$ & $26(8)$ & 75 (23) & $50(15)$ & $50(15)$ & $154(46)$ & $33(10)$ & $92(28)$ \\
\hline Model 1, ${ }^{\mathrm{C}}$ OR $(95 \% \mathrm{Cl})$ & $0.63(0.47-0.83)$ & $1.2(0.73-2.1)$ & $1.2(0.88-1.7)$ & $1.6(1.1-2.4)$ & $3.1(2.0-4.8)$ & $3.0(2.3-4.0)$ & $7.1(3.5-14)$ & $3.1(2.1-4.4)$ \\
\hline Model 2, OR (95\% Cl) & $0.69(0.51-0.91)$ & $1.2(0.68-2.0)$ & $1.2(0.81-1.6)$ & $1.5(1.0-2.3)$ & $2.8(1.7-4.4)$ & $2.9(2.2-3.9)$ & $6.4(3.2-13)$ & $2.9(2.1-4.2)$ \\
\hline Model 3, ${ }^{e}$ OR $(95 \% \mathrm{Cl})$ & $0.98(0.71-1.3)$ & $0.97(0.55-1.7)$ & $0.94(0.65-1.4)$ & $1.3(0.82-2.0)$ & $1.3(0.79-2.1)$ & $2.2(1.6-3.0)$ & $4.0(1.9-8.4)$ & $2.4(1.6-3.6)$ \\
\hline \multicolumn{9}{|l|}{ Weekly+ use $(n=190)$} \\
\hline$n(\%)$ & $113(60)$ & $27(14)$ & $42(22)$ & $43(23)$ & $42(22)$ & $139(73)$ & 55 (29) & $114(60)$ \\
\hline Model 1, ${ }^{\mathrm{C}}$ OR $(95 \% \mathrm{Cl})$ & $0.41(0.29-0.58)$ & $2.4(1.3-4.3)$ & $1.3(0.85-1.9)$ & $2.6(1.7-4.0)$ & $5.0(3.2-7.7)$ & $9.3(6.3-14)$ & $25(13-47)$ & $12(8.1-17)$ \\
\hline Model 2, ${ }^{d}$ OR $(95 \% \mathrm{Cl})$ & $0.50(0.34-0.73)$ & $2.1(0.97-4.4)$ & $1.2(0.77-1.8)$ & $2.2(1.3-3.6)$ & $3.9(2.4-6.4)$ & $8.6(5.7-13)$ & $21(11-41)$ & $11(7.2-16)$ \\
\hline Model 3, ${ }^{e}$ OR $(95 \% \mathrm{Cl})$ & $0.84(0.55-1.3)$ & $1.6(0.68-3.7)$ & $0.88(0.55-1.4)$ & $1.7(0.95-2.9)$ & $1.3(0.77-2.3)$ & $5.6(3.5-9.0)$ & $10(4.7-22)$ & $7.8(4.9-12)$ \\
\hline $\begin{array}{l}\text { GHQ, General Health Questio } \\
\text { a. Frequencies and percenta } \\
\text { b. Percentage of group with } \\
\text { c. Model 1: odds ratios (OR) } \\
\text { d. Model 2: as for Model 1, } \\
\text { e. Model 3: as for Model 2, }\end{array}$ & $\begin{array}{l}\text { ler adjustmer } \\
\text { ler adjustmer }\end{array}$ & istr & rett & ves $1-6$ & 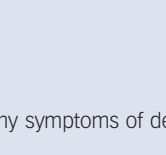 & - & 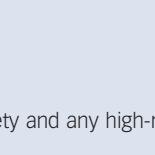 & (2) \\
\hline
\end{tabular}

problems than non-users and those who only began occasional use after adolescence.

Occasional adolescent cannabis use was associated with lower educational attainment, but this association was substantially attenuated after adjustment for adolescent tobacco use. It seems unlikely that tobacco smoking directly affects educational attainment but this finding does raise a possibility that the social milieu linked to both tobacco smoking and cannabis use may contribute to such outcomes. ${ }^{18}$ A recent study suggested that peer and parental influences that are linked to smoking during adolescence also predict poor school grades and thus smokers were more likely to have poorer academic outcomes. ${ }^{19}$

Adolescent cannabis use has become normative in many countries. In some, it may be linked to social competence, popularity and exploration of new experiences; in others, it may reflect low family connection, low school commitment and affiliation with a similarly disengaged peer group. Conversely, abstention may be the result of social reservedness. ${ }^{4,5,20}$ Continued occasional cannabis use was not related to later depression/ anxiety. In contrast, early and continued occasional cannabis use did predispose to later drug use.

This study was consistent with well-conducted, populationbased cohort study findings that the timing of cannabis use onset may also be important. ${ }^{21,22}$ Importantly, the current study found that even if early-onset cannabis use began and remained as occasional use, nonetheless, risks for drug use and drug use problems remained elevated. By studying the varying trajectories of use, this study has suggested that although a clear dose-response relationship exists between cannabis use and other outcomes, whereby regular users were most likely to have adverse outcomes during young adulthood, occasional adolescent-onset cannabis use that persists into young adulthood is clearly related to increased risks of some adverse outcomes, particularly drug use. The link between early-onset cannabis use and subsequent drug involvement - the so-called 'gateway effect' - has been the subject of much debate. ${ }^{23-25}$ Disagreement remains about the reasons why such associations persist, but researchers have proposed biochemical explanations that suggest that early-onset drug use might affect the maturing adolescent brain such that the user becomes more sensitive to (or disposed towards) other drug effects. ${ }^{26}$ Others suggest that learning and socially mediated processes are more important, whereby young users simply 'learn' to incorporate drug use into their lives and/or that use is accompanied by entry into social circles that are characterised by multiple types of drug use. ${ }^{23-25}$ Our findings regarding occasional use might be considered to be more consistent with psychosocial rather than biochemical mediation for the association, given the relatively infrequent exposure to the drug itself. ${ }^{26}$

\section{Strengths and limitations}

The main strengths of this study are its population-based sample and the frequent detailed measures of drug use and psychosocial outcomes over a 10 -year period. One limitation is that non-response in longitudinal studies is associated with drug use; however, we had relatively high participation rates and used multiple imputation to attempt to minimise non-response biases. All data were based on self-report which was not externally validated, but this has been accepted as an appropriate way in which to gain information about population behaviours. ${ }^{27,28}$ There were also no negative consequences for admitting to drug use. ${ }^{28}$

Some cannabis use may not have been 'captured' within assessment windows in the adolescent waves owing to the 6-month timeframes. This is probably minimal because of the very high levels of cannabis use that were nonetheless documented, and the similarity in levels compared with other young people assessed in Australia around the same timeframe. ${ }^{29}$ Wave 8 cannabis dependence may have been underestimated since only weekly+ users were assessed. However, comparison with Australian survey data found this was unlikely to occur. ${ }^{30}$ Finally, the small size of some groups limited the precision of some comparisons.

\section{Implications}

Occasional adolescent cannabis use was associated with higher levels of drug use in young adulthood compared with non-users. The confounding effect of tobacco use for a number of outcomes 
suggests possible mediating effects of underlying risk-taking behaviours in increasing risk for some adverse psychosocial outcomes. Exaggerated messages about severe harms of occasional cannabis use would be unfounded and at odds with the experience of this group. Yet interventions to reduce escalation of both cannabis and other drug use among occasional users do seem warranted. Given that occasional users are unlikely to present to specialised services, this message might be best delivered through screening in primary care or community-level health education. ${ }^{31}$

Louisa Degenhardt, PhD, National Drug and Alcohol Research Centre, University of New South Wales, Sydney, New South Wales; Carolyn Coffey, MSC, PhD, Centre for Adolescent Health, Murdoch Children's Research Institute, Melbourne, Victoria; John B. Carlin, PhD, Clinical Epidemiology \& Biostatistics Unit, Murdoch Children's Research Institute, and University of Melbourne Department of Paediatrics,

Melbourne, Victoria; Wendy Swift, PhD, National Drug and Alcohol Research Centre, University of New South Wales, Sydney, New South Wales; Elya Moore, PhD, Department of Microbiology and Infectious Diseases, Royal Women's Hospital, Melbourne, Victoria; George C. Patton, PhD, Centre for Adolescent Health, and Clinical Epidemiology \& Biostatistics Unit, Murdoch Children's Research Institute, Melbourne, Victoria, and University of Melbourne Department of Paediatrics, Melbourne, Victoria, Australia

Correspondence: Louisa Degenhardt, National Drug and Alcoho Research Centre, University of New South Wales, 2052, NSW, Australia. Email: I.degenhardt@unsw.edu.au

First received 7 Nov 2008, final revision 3 Aug 2009, accepted 21 Dec 2009

\section{Funding}

Funding has been provided by the Australian National Health and Medical Research Counci and the Australian Government Department of Health and Ageing. The funding body had no role in the design, analysis or interpretation of study findings, nor in the decision to submit this paper for publication.

\section{References}

1 Hall W, Degenhardt L, Lynskey M. The Health and Psychological Effects of Cannabis Use. NCADA Monograph No. 44. Australian Publishing Service, 2001

2 Moore $\mathrm{T}$, Zammit $\mathrm{S}$, Lingford-Hughes $\mathrm{A}$, Barnes $\mathrm{T}$, Jones $\mathrm{P}$, Burke $\mathrm{M}$, et al. Cannabis use and risk of psychotic or affective mental health outcomes: a systematic review. Lancet 2007; 370: 319-28.

3 Hall W, Degenhardt L. Prevalence and correlates of cannabis use in developed and developing countries (invited review). Curr Opin Psychiatry 2007; 20: 393-7.

4 Shedler J, Block J. Adolescent drug use and psychological health: a longitudinal inquiry. Am Psychol 1990; 45: 612-30.

5 Tucker J, Ellickson PL, Collins RL, Klein D. Are drug experimenters better than abstainers? A longitudinal study of adolescent marijuana use. J Adolesc Health 2006; 39: 488-94.

6 Paperny D, Aono J, Lehman R, Hammar S, Risser JC. Computer-assisted detection and intervention in adolescent high-risk health behaviours. J Paediatrics 1990; 116: 456-62.

7 National Health and Medical Research Council. Australian Guidelines to Reduce Health Risks from Drinking Alcohol. Australian Government Publishing Service, 2009

8 Coffey C, Carlin JB, Lynskey M, Li N, Patton GC. Adolescent precursors of cannabis dependence: findings from the Victorian Adolescent Health Cohort Study. Br J Psychiatry 2003; 182: 330-6.
9 Lewis G, Williams P. Clinical judgement and the standardized interview in psychiatry. Psychol Med 1989; 19: 971-9.

10 Lewis G, Pelosi A, Araya R, Dunn G. Measuring psychiatric disorder in the community: a standardized assessment for use by lay interviewers. Psychol Med 1992; 22: 465-86.

11 Harrington $\mathrm{R}$, Fudge $\mathrm{H}$, Rutter $\mathrm{M}$, Pickles $\mathrm{A}$, Hill J. Adult outcomes of childhood and adolescent depression: II. Links with antisocial disorders. J Am Acad Child Adolesc Psychiatry 1991; 30: 434-9.

12 Goldberg D. The Detection of Psychiatric Illness by Questionnaire. Oxford University Press, 1972

13 Fagerstrom KO, Heatherton TF, Kozlowski LT. Nicotine addiction and its assessment. Ear Nose Throat J 1991; 69: 763-6.

14 World Health Organization. Composite International Diagnostic Interview (CIDI core) Version 2.1 (12-month version). WHO, 1997.

15 Schafer JL. Analysis of Incomplete Multivariate Data. Chapman and Hall, 1997.

16 Bernaards CA, Belin TR, Schafer JL. Robustness of a multivariate normal approximation for imputation of incomplete binary data. Stat Med 2007; 26 1368-82.

17 Carlin JB, Galati JC, Royston P. A new framework for managing and analysing multiply imputed data in Stata. Stata J 2008; 8: 49-67.

18 Mathers M, Toumbourou J, Catalano R, Williams JB, Patton G. Consequences of youth tobacco use. A review of prospective behavioural studies. Addiction 2006; 101: 948-58.

19 Tucker J, Martinez JP, Ellickson PL, Edelen M. Temporal associations of cigarette smoking with social influences, academic performance and delinquency: a four wave longitudinal study from ages 13 to 23. Psychol Addict Behav 2008; 22: 1-11.

20 Suris J, Akre C, Berchtold A, Jeannin A, Michaud P-A. Some go without a cigarette. Arch Pediatr Adolesc Med 2007; 161: 1042-7.

21 Brook JS, Balka EB, Whiteman M. The risks for late adolescence of early adolescent marijuana use. Am J Public Health 1999; 89: 1549-54.

22 Kandel DB, Yamaguchi $\mathrm{K}$, Chen $\mathrm{K}$. Stages of progression in drug involvement from adolescence to adulthood: further evidence for the gateway theory. J Stud Alc 1992; 53: 447-57.

23 Hall W. Dissecting the causal anatomy of the link between cannabis and other illicit drugs. Addiction 2006; 101: 472-3.

24 Fergusson D, Boden J, Horwood LJ. Cannabis use and other illicit drug use: testing the cannabis gateway hypothesis. Addiction 2006; 101: 556-66.

25 Morral A, McCaffrey D, Paddock S. Reassessing the marijuana gateway effect. Addiction 2002; 97: 1493-504

26 Schenk S. Sensitization as a process underlying the progression of drug use via gateway drugs. In Stages and Pathways of Drug Involvement: Examining the Gateway Hypothesis (ed D Kandel): 318-36. Cambridge University Press, 2002.

27 Fendrich M, Mackesy-Amiti ME, Johnson TP, Hubbell A, Wislar JS. Tobaccoreporting validity in an epidemiological drug-use survey. Addict Behav 2005; 30: $175-81$.

28 Harrison L. The validity of self-reported drug use in survey research: an overview and critique of research methods. NIDA Res Monogr 1997; 167: 17-36.

29 Australian Institute of Health and Welfare. National Drug Strategy Household Survey 2004: Detailed Findings. AlHW, 2005 (http://www.aihw.gov.au/ publications/phe/ndshsdf04/ndshsdf04.pdf).

30 Coffey C, Carlin J, Degenhardt L, Lynskey M, Sanci L, Patton G. Cannabis dependence in young adults: an Australian population study. Addiction 2002; 97: 187-94.

31 Toumbourou J, Stockwell T, Neighbors C, Marlatt G, Sturge J, Rehm J. Interventions to reduce harm associated with adolescent substance use Lancet 2007; 369: 1391-401. 